\title{
Atrás de la escena tipográfica: los impresores en la Nueva España *
}

\author{
Idalia García **
}

Artículo recibido:

5 de diciembre de 2013.

Artículo aceptado:

30 de abril de 2014.

\section{Resumen}

La historia de la imprenta tipográfica en la Nueva España es un tema aparentemente bien conocido y por tanto bien trabajado, pero lo cierto es que todavía falta mucho por conocer y, en parte, se debe a que los impresores no dejaron muchos testimonios de sus actividades y otros más se han perdido con el tiempo. Este texto analiza el nivel de conocimiento que actualmente tenemos sobre esta práctica profesional que fue responsable de la producción bibliográfica durante casi trescientos

* Una primera versión de este trabajo se presentó en el XVI Encuentro de Investigadores del Pensamiento Novohispano Roberto Heredia Correa (Universidad Nacional Autónoma de México, Instituto de Investigaciones Filológicas e Instituto de Investigaciones Bibliográficas, ciudad de México, 6 al 8 de noviembre de 2013), con el título Tras bambalinas de letras: los impresores de la Nueva España.

** Instituto de Investigaciones Bibliotecológicas y de la Información de la UNAM, México.pulga@iibi.unam.mx

INVESTIGACIÓN BIBLIOTECOLÓGICA, Vol. 29, Núm.66, mayo/agosto, 2015, México, ISSN: 0187-358X. pp. 105-137 
años. Nos interesa enfatizar aquellas certezas que se han repetido con el tiempo, y de las cuales no tenemos ninguna noticia documental o bibliográfica conservada como la actividad gremial o la aplicación de las leyes de imprenta en territorio americano. Se pretende trasladar nuestra interpretación histórica hacia las prácticas culturales de los hombres y las mujeres que producían una mercancía tanto alabada como perseguida.

Palabras clave: Imprenta Tipográfica Novohispana; Impresores Novohispanos; Cultura Escrita en la Nueva España.

\section{Abstract}

Printers in New Spain: behind the scenes of printing and typesetting

Idalia García

The history of the typographic printing press in the New Spain is a well-known topic that has been thoroughly examined. It is remarkable, however, that printers did not leave behind many first-hand reports of their professional practice. This study examines current knowledge of New Spain printing and typesetting practices, which is responsible for three-hundred years of bibliographic production. The study, moreover, takes a critical look at those accepted "certainties" regarding printing and typesetting, which in fact have little bibliographical or documentary support, for example, the wide-spread assumptions regarding guild practices. The study proposes a historical interpretation of the cultural practices of men and women.

Keywords: Typographic print in New Spain; Journeymen-Printers in New Spain; Cultural Written in New Spain. 
...sin los libros faltara la noticia y la memoria... Son viandas muy provechosas y saben a todo. De ellos procede la conformidad, y quietud del animo, necesaria en los tiempos, y ocasiones de aprieto. Obran consuelo en la melancolia, en las aflicciones y en los trabajos.

Melchor de Cabrera, 1675

\section{INTRODUCCIÓN}

T os libros, como muchos objetos culturales, formaron y forman parte de Lla vida cotidiana de las personas en muchas sociedades. Por esa razón han sido objeto de interés para la investigación especializada, que ha desarrollado un campo de conocimiento muy especial: el de la cultura escrita. En este campo, en el que interviene la participación de múltiples disciplinas, el libro es analizado en función de los modos de producción, las redes comerciales que hicieron posible su circulación y comercio, la conformación de bibliotecas o gabinetes de lectura, el intrincado mundo de los lectores y la transmisión de los objetos bibliográficos hasta su custodia contemporánea. De esta manera los diferentes países se han acercado al conocimiento de la cultura escrita de su pasado, al mismo tiempo que han valorado la producción de impresos antiguos que se han conservado en los repositorios públicos y privados. Por esta razón no resulta extraño que en el siglo XIX se favoreciera el desarrollo de grandes proyectos de catalogación de documentos y de libros que dan testimonio de las características de esa cultura.

En nuestro país el conocimiento de esa cultura escrita no ha generado tanto interés como en otras latitudes, a lo que se suma una situación desigual en los procesos de registro en los archivos y bibliotecas de todo el escenario nacional, especialmente en el caso de esos archivos donde el registro no se realiza de forma homogénea y en conformidad con las tendencias internacionales. Tal condición dificulta, mas no imposibilita, la investigación, pues varios de estos temas históricos no cuentan con numerosas fuentes documentales por motivos diferentes a la conservación o la valoración de los documentos. Básicamente se trata de la localización de los testimonios históricos y de la garantía de su permanencia en las instituciones de custodia. En efecto, una parte considerable de la investigación tiene poco interés en recuperar nuevas fuentes históricas, o en su defecto de verificarlas, y es probable que esta situación se vea afectada precisamente por la realidad institucional de los repositorios.

Dicha condición, desastrosa en algunos casos, no puede compararse con el avance que han alcanzado los repositorios de otras latitudes, en donde se 
cuenta con buenos instrumentos de consulta en tanto que son confiables para la investigación, o porque garantizan la permanencia de los testimonios custodiados. Podemos citar varios ejemplos de estas piezas "flotantes o desaparecidas" que algunos investigadores de los repositorios mexicanos siguen buscando con esperanza, o los casos en los que el objeto conservado no coincide con el registro. Problemática institucional de gran importancia que aquí no podemos abordar por no ser la intención de esta reflexión. Sólo queremos apuntar que este es uno de los aspectos que podrían explicar el tipo de desarrollo que tienen los estudios de historia escrita en nuestro país, y que quizá también influyan en que la cultura escrita no sea una temática común en la formación profesional de algunas disciplinas humanísticas y de las ciencias sociales.

En esta orientación queremos referirnos al conocimiento histórico que tenemos sobre las personas que participaron en la producción y circulación de los libros en la Nueva España. Ciertamente no conservamos muchos documentos de la actividad profesional y familiar de estas personas, cuyas evidencias históricas también se verían afectadas por los riesgos que esas actividades implicaban, básicamente debido al control inquisitorial que ejerció el Santo Oficio. La mayoría de los testimonios localizados han sido publicados en varias ocasiones desde principios del siglo XX. Sin embargo, los archivos nacionales y extranjeros todavía deparan sorpresas sobre la actividad tipográfica en la Nueva España, pues no debemos olvidar que éstos se ocupaban de una de las mercancías más vigiladas y que se consideraba el vehículo propicio de la herejía: el texto escrito, fuese éste impreso o manuscrito. No en vano ciertos periodos fueron críticos para los operarios de prensa o para los libreros, muchos de los cuales no pudieron evitar los juicios inquisitoriales pues estaban "en el peor de los sitios y de los momentos". ${ }^{1}$

Esta realidad marcada por la denuncia y la sospecha afectaba a un número importante de personas dedicadas al mundo del libro. Realidad que, hasta donde tenemos noticia, tuvo prácticamente las mismas características legales que se practicaban en la península ibérica. La Nueva España fue un territorio bajo el gobierno de la monarquía española y por tanto sujeto a las leyes que de ésta emanaron, ya fuesen generales o específicas. Además de esta realidad jurídica y comercial, se imponía otra de naturaleza sociocultural que también influyó notablemente en las mentalidades de la época. Nos referimos al ya mencionado Tribunal del Santo Oficio o más comúnmente conocido como la Inquisición. Durante el siglo XVI, esta institución de origen medieval había cobrado un enorme poder político que le permitió imponer mecanismos pa- 
ra el control de los impresos y de los manuscritos que se elaboraron y circularon durante casi tres siglos, hasta su tormentosa extinción institucional a cargo de las Cortes de Cádiz. Ciertamente la Inquisición tenía toda su atención puesta sobre impresores, operadores de prensa y libreros porque los objetos que producían y comerciaban eran considerados extremadamente riesgosos para la ortodoxia religiosa. Así lo expresaban más de uno de los teóricos que defendían esta postura y que incluso se manifestaba en los edictos, instrucciones e índices elaborados para tal efecto.

Pero debemos recordar que la acción inquisitorial sólo podía aplicarse a libros en circulación, puesto que el control sobre su producción había sido confiado a las autoridades civiles desde la promulgación de la Pragmática de $1558 .^{2}$ De esta manera los inquisidores sólo podían opinar antes de que se distribuyeran los textos de su competencia o temática. Ahora bien, la Inquisición actuaba contra los impresores porque éstos dedicaban parte de su negocio a la venta de los libros y en este sentido también participaban en los procesos de distribución tal como hacían los mercaderes de libros. También es importante anotar que la Inquisición española y, por tanto los tribunales americanos, tenían una idea diferente de la Inquisición romana respecto a los libros prohibidos y expurgados. Este último tipo de censura fue la más común en los territorios hispanoamericanos y como testimonio existen numerosos libros antiguos que poseen una anotación manuscrita en portada, guarda anterior o en el verso de la portada, como la que aquí se transcribe:

Corregido por orden del Sto. Officio segun el expurgatorio del año de 1707. Convento de N. P. S. Domingo de Mexico en 7 de septiembre de 1716 años M. fr. Estevan Navarro. ${ }^{3}$

Dicha inscripción manuscrita tiene su contraparte documental como testimonio del proceso del que es resultado. Recientemente hemos localizado un expediente conservado en el Archivo General de la Nación que nos permite comprender, en cierta manera, cómo se hacían las visitas inquisitoriales a las instituciones religiosas de la Nueva España para buscar los libros prohibidos y expurgados. ${ }^{4}$

2 Fermín de los Reyes Gómez, El libro en España y América, legislación y censura: siglos XV y XVIII, pp. 193-207.

3 Anotación manuscrita en la portada del libro Charles Estienne, Dictionarivm historicum poeticum..., Lugduni: Apud Johannem Pillehotte sub signo nominis Iesv, 1603. Ejemplar de la Biblioteca Nacional de México RFO 913.38 EST.d 1603, el cual tiene marca de fuego dominica en el canto superior.

4 Idalia García, "Tentaciones herejes en instituciones religiosas: el control inquisitorial en las bibliotecas novohispanas". 
Para quienes sostenían y argumentaban a favor de la vigilancia inquisitorial, todo lo que afectaba al comercio del libro debía ser puntualmente observado porque era la única forma de evitar que los cristianos se contagiaran de la herejía, "cuya expansión ha sido facilitada de manera extraordinaria con la aparición de la imprenta". ${ }^{5}$ Por esta razón la historia de esos hombres y mujeres que hicieron posible la impresión de libros resulta fascinante y sin duda es muy diferente a la de otras personas de su entorno social y cultural; eran el resultado de un enorme esfuerzo por sobrevivir a un tiempo demasiado adverso y aun así conseguir mantener la empresa familiar que, de funcionar, daría sustento a más de un generación.

\section{LOS HOMBRES Y MUJERES DE LAS PRENSAS NOVOHISPANAS}

En materia de impresos antiguos, es muy probable que los libros producidos en la Nueva España sean tan interesantes como los incunables. Lo cual no resulta extraño ya que se trata de los primeros libros fabricados con prensas manuales en toda América. De ahí que aparentemente sepamos casi todo de las prensas tipográficas que funcionaron en el territorio novohispano entre el siglo XVI y las primeras décadas del siglo XIX. ${ }^{6}$ Una historia que comienza con Juan Pablos, operario de la casa sevillana de los Cromberger, quien en 1539 fue el encargado de instalar la primera prensa en América y dio inicio a la producción de impresos, y que termina con Alejandro Valdés, al parecer el último operario de una prensa manual y uno de los primeros empresarios de imprentas mecánicas del siglo XIX. Alejandro fue hijo de Manuel Antonio Valdés, quien fundó el taller de imprenta en la calle de Santo Domingo en 1808. ${ }^{7}$ Alejandro se hizo cargo de la imprenta de su padre dos años después de esa fecha. ${ }^{8}$

Sin embargo, tal conocimiento resulta problemático si comparamos aquello que creemos saber con los desarrollos de conocimiento que se tienen en otros países en la compleja temática de la cultura escrita. ${ }^{9}$ En esos países existe una producción bibliográfica en constante aumento que da cuenta de un interés temático que resulta complicado mencionar aquí, pero que se aprecia en libros y revistas especializadas (como The Gutenberg-Jahrbuch, Cultura Escrita E

5 Enrique Gacto, "Libros venenosos. Sobre los principios doctrinales de la censura inquisitorial", p. 29.

6 Idalia García, Secretos del estante: elementos de descripción bibliográfica del libro antiguo, pp. 173-210.

7 José Joaquín Fernández de Lizardi, Obras, pp. 13-344.

8 José Toribio Medina, Historia de la imprenta en los antiguos dominios españoles de América y Oceanía.

9 Martin Lyons, "New directions in the History of Written Culture"; Carlos Alberto González Sánchez, "Cultura escrita y nueva historia cultural: paradigmas y realidades". 
Sociedad o Book History, entre otras), o en eventos temáticos, sociedades científicas (Society of the History Authorship, Reading and Publishing), y en departamentos de investigación en muchos centros universitarios de países como España, Italia, Francia, Inglaterra, Bélgica, Alemania, Canadá o los Estados Unidos, por mencionar los más importantes. ${ }^{10}$ En efecto, del siglo XVI novohispano contamos con poca información por cada impresor activo del periodo comenzado con Juan Pablos, ${ }^{11}$ Antonio de Espinosa, ${ }^{12}$ Pedro Ocharte, ${ }^{13}$ Pedro Balli, ${ }^{14}$ Antonio Ricardo, ${ }^{15}$ Melchor Ocharte, quien fue hijo de Pedro Ocharte y es considerado un impresor menor dedicado a tesis universitarias, ${ }^{16}$ y Enrico Martínez, el último impresor del siglo XVI y primero del XVII. ${ }^{17}$

Ahora bien, si nos adentramos en el siglo XVII podemos apreciar que ya no existen tantos trabajos dedicados a cada uno de los talleres de imprenta que hubo en la Nueva España; en ese periodo tan sólo existían cuatro talleres hacia $1620 .{ }^{18}$ Pero tiempo más adelante la nómina de impresores aumentó considerablemente. Así encontramos como heredero de Martínez a su hijo Juan Ruiz, pero también a Luis Ocharte Figueroa, Diego López Dávalos, Jerónimo Balli, Diego Garrido y su viuda, Juan Blanco de Alcazar, Pedro y Diego Gutierrez, Francisco Salvago, Pedro de Quiñones, Francisco Robledo, Hipólito Rivera, Agustín de Santiesteban, Francisco Rodríguez Lupercio y su viuda, Juan de Ribera y su viuda, Juan José Guillena Carrascosa y, por supuesto, la familia de Bernardo Calderón. Este último fue el primero de la zaga de impresores más larga en la historia de la Nueva España, la cual terminó en 1810 con la imprenta de María Fernández de Jáuregui. ${ }^{19}$ No se puede negar lo interesante que resulta observar el escaso interés histórico que han

10 Simon Elliot y Jonathan Rose (eds.), A Companion to the History of the Book.

11 Agustín Millares Carlo y Julián Calvo, Juan Pablos: primer impresor que a esta tierra vino; María Isabel Grañén Porrúa, Los grabados en la Obra de Juan Pablos: primer impresor de la Nueva España.

12 Alexander Stols, Antonio de Espinosa: el segundo impresor mexicano; Juan Pascoe, La obra de Enrico Martínez.

13 Alexander Stols, Pedro Ocharte: el tercer impresor mexicano.

14 María del Refugio Paisano Rodríguez, Pedro Balli, cuarto impresor novohispano: estudio bistórico-bibliotecológico.

15 Este impresor trabajó desde 1577 y hasta 1579 para los jesuitas en el Colegio de San Pedro y San Pablo; posteriormente se trasladó a Perú y ahí fue el primer impresor desde 1584 una vez que obtuvo el privilegio necesario del rey Felipe II. José Toribio Medina, La imprenta en México, 1539-1821, t. 1, pp. XCIII-CVII; Víctor Cid Carmona, Antonio Ricardo: impresor de dos ciudades, México y la Ciudad de los Reyes.

16 Medina, op. cit., pp. CVIII-CIX.

17 Francisco de la Maza, Enrico Martínez: cosmógrafo e impresor de Nueva España.

18 Ana Carolina Ibarra, "El desarrollo de la imprenta", p. 76.

19 Esto es lo que ha demostrado la documentación localizada por Ana Cecilia Montiel Ontiveros para su tesis de Doctorado, en donde se comprueba que, a falta de heredero directo de los Calderón, el taller fue entregado a uno de sus sobrinos de apellido Jáuregui. Montiel Ontiveros, La imprenta de María Fernández de Jáuregui: testigo y protagonista de los cambios en la cultura impresa durante el periodo 1801-1817 en México. 
generado estas personas del siglo XVII, quizá el periodo menos trabajado, ya que exceptuando a los Calderón, que han sido objeto de una disertación de doctorado, ${ }^{20}$ no encontramos otros textos dedicados específicamente a cada uno de estos talleres, a su producción ni a recuperar la historia de quienes ahí trabajaron.

Tal desinterés de investigación también se mantiene, con escasas excepciones, para los impresores del siglo XVIII, entre quienes encontramos a los herederos de la viuda de Francisco Rodríguez Lupercio, Francisco y Miguel de Ribera Calderón (los herederos de Bernardo Calderón), la viuda y los herederos de este último, los herederos de Guillena Carrascosa, Juan Francisco de Ortega y Bonilla, Joseph de Jáuregui y sus herederos, José Bernardo de Hogal, su viuda, los herederos de ésta y José Antonio de Hogal, ${ }^{21}$ María de Rivera y sus herederos, Francisco Javier Sánchez Pizero, José Ambrosio de Lima, Nicolás Pablo de Torres, Cristóbal y Felipe de Zúñiga y Ontiveros de quienes se ocupa otra tesis, ${ }^{22}$ Mariano José de Zúñiga y Ontiveros, Gerardo Flores Coronado, José Francisco Dimas Rangel, José Fernández de Jáuregui y la citada María Fernández de Jáuregui. También en este siglo aparecen otro tipo de imprentas como la del Real Colegio de San Ildefonso, ${ }^{23}$ o la imprenta de la Biblioteca Mexicana donde se produjo el primer volumen de la magna obra de Eguiara y Eguren.

Cierto, no contamos con un trabajo semejante al que elaboró Delgado Casado $^{24}$ para registrar todos los datos profesionales y personales de cada uno de los hombres y mujeres que imprimieron en los talleres tipográficos de la Nueva España. Quizá sea una tarea que no se considera importante porque, no debemos olvidar, una parte fundamental de esos datos se extrae de la magna obra de Toribio Medina. ${ }^{25}$ Por tanto queda como tarea pendiente y necesaria la actualización de la obra de Medina, para recuperar los datos biográficos y profesionales que actualmente conocemos de las imprentas novohispanas: tarea que debería incluir toda la bibliografía producida sobre esa temática.

20 Kenneth C. Ward, Where They Coin Money and Print Books: The Calderón Family Printing Dynasty, 1631-1732.

21 María Justina Sarabia Viejo, "La imprenta Hogal: religión y cultura ilustrada en el México del siglo XVIII".

22 Manuel Suárez Rivera, Felipe y Mariano de Zúniga y Ontiveros: impresores ilustrados y empresarios culturales (1761-1825).

23 Martha Ellen Whittaker, Jesuit Printing in Bourbon Mexico City. The Press of Colegio de San Ildefonso, 1748-1767.

24 Juan Delgado Casado, Diccionario de impresores españoles, siglos XV-XVII.

25 Medina, op. cit. 
Todo lo anterior sin referirnos a los verdaderos artesanos del libro: los operarios de prensa como Cornelio Adriano César, a quien sí se ha dedicado un libro que lamentablemente fue de escasa distribución y por tanto de escaso conocimiento. ${ }^{26}$ Cornelio es quizá el más emblemático componedor en esta historia americana de la tipografía, pues se trasladó desde Harlem (Holanda) a la Nueva España en 1572 con toda la intención de fundar un taller de imprenta tras haber aprendido el oficio en el taller de Cristóbal Plantino. Sin embargo, su socio comercial, Guillermo Enríquez, lo denunció por luterano ante la Inquisición en $1598 .{ }^{27}$ A partir de su proceso inquisitorial nunca pudo establecer ese taller cuyo material finalmente fue utilizado por Enrico Martínez. A Cornelio, después de cumplir su condena, no le quedó más remedio que convertirse en operario de prácticamente todas las prensas en funcionamiento a final del siglo XVI y la segunda mitad del XVII, con excepción de la que estableció Antonio Ricardo. ${ }^{28}$

Esa realidad que Cornelio vivió como castigado de la Inquisición nos ha dejado varios testimonios muy interesantes sobre su trabajo y su vida personal, pues el propio componedor escribió numerosas cartas relacionadas directamente con los efectos que se derivaban del castigo impuesto por ser luterano; por ejemplo, la opinión que tenía respecto a la petición que le había hecho el padre guardián del Convento de Santiago Tlatelolco. Este franciscano había solicitado a Cornelio que enseñara su oficio a los indígenas del citado convento. Esta historia, varias veces ya transmitida, siempre se ha destacado como una opinión sobre las capacidades de los indígenas. En realidad se trata de una preocupación natural de Cornelio sobre el aumento de personas con conocimientos de impresión, y de la forma en que él se ganaría la vida al terminar su sentencia.

Este comentario lo escribió en 1604. Hoy podríamos decir que estuvo plenamente justificado pues en 1622 escribió otra carta sobre el tercer pleito que tuvo con Juan Blanco de Alcázar en la imprenta de los herederos de Diego López, cuando Blanco expresó que él debía ser el único impresor con "palabras feas y deshonestas". Se trata de una discusión que cuestiona su honor y sus habilidades profesionales, y el miedo que tiene de que le quiten su

26 Juan Pascoe, Cornelio Adrián César, impresor en México. Por fortuna, recientemente la biblioteca del Instituto de Investigaciones Bibliotecológicas y de la Información de la UNAM adquirió un ejemplar de esta edición de autor numerada. Dicha edición resulta muy interesante porque su autor ha recopilado y transcrito prácticamente todos los testimonios históricos que dan cuenta de la vida y actividad profesional de este singular personaje, así como la reproducción facsimilar de varias de sus obras. Esta disponibilidad ayudará a mejorar nuestra comprensión y conocimiento del trabajo de los talleres de imprenta novohispanos.

27 Archivo General de la Nación (en adelante AGN), Inquisición vol. 165, exp. 5 y vol. 166, exp. 2.

28 Pascoe, op. cit., p. 7. 
oficio pues teme por su mujer y sus "cinco criaturitas". ${ }^{29}$ Por eso pide justicia a quienes cree que pueden y deben ayudarle. Estos son curiosamente los inquisidores, quienes sabían que estaba tan capacitado como para ganar 4 pesos diarios. Este tipo de testimonios resultan invaluables incluso para darnos una idea de las penurias personales de los oficiales.

Por otro lado, el trabajo de Cornelio Adriano quedó estampado en numerosas portadas y tesis impresas, razón por la cual Pascoe supone que algunos de los impresores para quienes trabajó sólo fueron administradores de prensa y no operarios. Seguramente Cornelio participó en la formación de las nuevas generaciones de personas que alimentaron los talleres de prensa; sin embargo, sólo se conoce el nombre de uno de sus aprendices: Juan Fresco. ${ }^{30}$ Cornelio tuvo siempre ventaja frente a los otros operarios e impresores, porque como afirma Pascoe, construyó su propia prensa y los aparejos necesarios para su funcionamiento.

Sin embargo, existen otros operarios de cuya vida se conocen escasos datos, como la del esclavo Pedro que ejercía como tirador, los prensistas o tiradores Gil Barbosa y Tomé Rico, o el componedor Juan Muñoz, todos ellos operarios de Juan Pablos. ${ }^{31}$ Éste mismo no fue un erudito ni un universitario sino un operador como cualquier otro. Es más, en Sevilla declaró que "no sabía escribir su propio nombre". ${ }^{2}$ Pero también se encuentran Pedro Balli como corrector de pruebas; Adrián, componedor y cajista; Francisco Hernández, corrector y capataz, todos ellos de Pedro Ocharte; Juan Ortiz y Samuel Stradanus, los dos grabadores (el primero francés y el segundo flamenco); Esteban Álvarez, administrador y albacea de los Hogal, o Juan de Ávila, administrador de la imprenta de la Bibliotheca Mexicana, entre tantos otros que prácticamente son desconocidos o todavía no han sido del todo identificados. No olvidemos que estos personajes fueron los artífices de la cultura escrita en la Nueva España, no sólo por su producción sino especialmente porque su actividad posibilitó un importante comercio con las redes de distribución de libros europeos hacia todos los rincones del territorio novohispano. Esto es posible afirmarlo precisamente estudiando las memorias de libros institucionales y de particulares que todavía se conservan y que dan cuenta del rico contenido de las bibliotecas novohispanas.

Ahora bien, para ejemplificar las ausencias de conocimiento al que nos referimos, podemos citar un solo ejemplo: Medina reconoce en su obra ci-

29 AGN, Inquisición vol. 335, exp. 11, fol.126r.

30 Pascoe, op. cit., p. 104.

31 Millares y Calvo, op. cit., pp. 18 y 24

32 Clive Griffin, Los Cromberger: la historia de una imprenta del siglo XVI en Sevilla y Mejico, p. 120. 
tada que no conoce o no logra determinar el nombre de la viuda de Joseph Bernardo de Hogal. ${ }^{33}$ Cuestión interesante, pues efectivamente fue la única de las viudas novohispanas que nunca estampó su propio nombre en las portadas de los libros que produjo. Si bien se han conservado en México algunos documentos con el nombre de esta viuda en los que se encuentra su firma, el desconocimiento de su nombre no había permitido relacionarla con el impresor Hogal. La respuesta a este misterio fue la localización, en el Archivo General de Indias en Sevilla, del documento conocido como licencia de pasajeros de Rosa Teresa de Poveda, en donde además se conserva una carta personal de su marido y un impreso que nunca había sido registrado. ${ }^{34}$ Esta nueva información permite realizar estudios que aportan mayores datos o incluso nuevas dudas, pero también muestra que pese a lo que se cree es éste un campo temático que tiene mucho que ofrecer.

\section{EN LAS ENTRAÑAS DE LAS IMPRENTAS: PROCESOS DE PRODUCCIÓN Y OPERARIOS}

Son precisamente las viudas impresoras quienes más cuestionan nuestro conocimiento de las imprentas como talleres de producción y cuya historia desafía aquello que hemos supuesto como realidades concretas respecto al lugar de la mujer en términos jurídicos, sociales y profesionales. ${ }^{35}$ No debemos olvidar que hablamos de un periodo que se desarrolló entre $1540^{36}$ y $1833 ;^{37}$ es decir, casi trescientos años que abarcan la impresión de libros en la capital del virreinato desde 1539, Puebla en 1642, Oaxaca en 1720, Guadalajara en 1793 y Veracruz en 1794. Es decir, una ausencia más de conocimiento para un conjunto mayor de objetos de estudio si sumamos el necesario análisis de todos los talleres poblanos, incluyendo la producción y la vida de los impresores, empezando por quienes migran desde la ciudad de México como el caso de Francisco Robledo o Juan Blanco de Alcázar. ${ }^{38}$

33 Medina, op. cit., p. CLXX.

34 Idalia García, "Retazos en la vida de una impresora novohispana: Rosa Teresa de Poveda, viuda de Hogal”.

35 Silvia Marina Arrom, "Historia de la mujer y de la familia norteamericanas".

36 Fecha del Manual de adultos, del que se conservan dos hojas y entre ellas el colofón. Texto disponible en la Biblioteca Digital Hispánica, http://bdh.bne.es/bnesearch/ [Fecha de consulta: junio 2013].

37 Rosalba Cruz Soto, "Los periódicos del primer periodo de vida independiente (1821-1836)", p. 63.

38 Kenneth C. Ward, "Conjeturas sobre los orígenes de la imprenta en Puebla”, p. 179. 
Lo mismo puede decirse de los oaxaqueños, ${ }^{39}$ los tapatíos ${ }^{40}$ y los veracruzanos, tan sólo por citar los activos hasta el siglo XVIII; pero es posible que muchas prensas tipográficas se hayan mantenido produciendo en el territorio del México independiente hasta la tercera década del siglo XIX. Una cuestión que sólo se puede determinar analizando la estructura material de los impresos antiguos y comparando los ejemplares supervivientes, pues este tipo de producción se caracteriza por la presencia de variantes en las ediciones denominadas emisiones y estados, que son "alteraciones producidas en la composición de la que son resultado, ya sea en los procesos de imposición o de tirada, modificando la forma primaria". ${ }^{41}$ Esta es una tarea muy importante aunque sea engorrosa para el conocimiento de la cultura escrita, que no suele practicarse y que es toda una novedad, ${ }^{42}$ y la cual también resulta crucial para el control del patrimonio bibliográfico en nuestro país.

Por otro lado, siempre se ha considerado que la imprenta antigua fue una empresa con muchos riesgos y aparentemente pocos beneficios, que sólo podía funcionar si se disponía de un privilegio real. ${ }^{43}$ Lo cierto es que ese privilegio no fue necesario para todos los impresores, sino sólo para aquéllos que dieron inicio a un mercado en un territorio específico como es el caso de Juan Pablos. Precisemos que el privilegio no era suyo sino de Cromberger, y que aquél ayudaba comercialmente. Juan Pablos obtuvo la merced del virrey Antonio de Mendoza, misma que había sido prorrogada por el virrey Luis de Velasco hasta 1558. Por esa razón, Antonio de Espinosa pudo impugnar esas mercedes pues nadie podía poner impedimento alguno para ejercer el oficio de impresor, porque debía ejercerse "[...] libremente en esa tierra como se vsa en estos reynos". Así se reconoce en la Cédula Real concedida a Antonio de Espinosa en $1559 .{ }^{44}$

Estas concesiones de la autoridad representan otro problema de conocimiento que debemos determinar con claridad. Kenneth Ward ha denominado acertadamente a este tipo de privilegio como "de monopolio", para el que incluía el derecho de imprimir un tipo de obra como cartillas o confesionarios, y también el de no dejar de imprimir e impedir que otros impre-

39 María Isabel Grañén Porrúa y Juan Pascoe, Francisca Flores y la imprenta en Oaxaca, 1685 1720; Juan Pascoe, José María Idiáquez, impresor en el Oratorio de la Congregación de San Felipe Neri de Oaxaca.

40 Carmen Castañeda García, Imprenta, impresores y periódicos en Guadalajara, 1793-1811.

41 Idalia García, Secretos del estante: elementos de descripción bibliográfica del libro antiguo, p. 207.

42 Guadalupe Rodríguez Domínguez, "Avance para una nueva tipobibliografía mexicana: sobre la Doctrina de Gante y el Vocabulario de Molina, impresos por Juan Pablos".

43 Laura Suárez de la Torre, "La producción de libros, revistas, periódicos y folletos en el siglo XIX", p. 10. Bibliografía mexicana del siglo XVI, pp. 49-50 (documento 33) y p. 51 (documento 39). 
sores imprimieran el mismo tipo de obra y la difusión de éstas. ${ }^{45}$ Esta idea de Ward se diferencia del privilegio para los libros que se daba en España y que se podía dar para la impresión de una obra, como el que se concedió al jesuita Antonio Ruiz de Montoya "por tiempo de diez años, para imprimir un libro intitulado Conquista espiritual, hecha por los religiosos de la Compañía de Jesus", 46 fechado en 1639. También se daban privilegios para imprimir y distribuir el mismo libro, como el caso del privilegio otorgado al licenciado Cambero en 1720 para "imprimir y vender por tiempo de diez años, un libro, intitulado, el Heroe Serafico San Pedro de Alcantara”. ${ }^{4}$

El privilegio que otorgaba la Corona, tanto para la impresión como para la distribución, podía dar cierta exclusividad a aquella persona que lo ejercía en el territorio para el que se otorgaba, pero no invalidaba de forma definitiva las impresiones de otros talleres. No obstante la tramitación y obtención del privilegio resultaba bastante problemática, porque implicaba numerosas negociaciones comerciales y políticas según el tipo de intereses de los que se tratase. ${ }^{48}$ Sin embargo, el último trabajo de Fernando Bouza muestra que el privilegio no se otorgó en esa dualidad mencionada de forma exclusiva, sino que existen tipos más complejos que incluirían la prórroga, revocación o introducción de libros impresos en otros territorios. ${ }^{49}$

En este sentido, se puede llamar privilegio si el documento emana de la figura del rey; es decir, en origen se trata de una cédula real y, por tanto, de un documento emitido por el rey de España o quien ejerza el gobierno y sus consejos, mientras que los documentos del virrey en la Nueva España deben denominarse como Reales Provisiones. ${ }^{50}$ Esto es así porque la estructura del poder del virreinato no responde a una centralización sino que "obedecía a una lógica en la que cada institución disponía de un poder y jurisdicción propios". 51

Ciertamente el virrey es una imagen del rey dotada de la majestad y del poderío del monarca, pero no puede sustituirlo ante el poder de la Iglesia,

45 Ward, op. cit., p. 176.

46 Antonio Ruiz de Montoya (S. I.), Conquista espiritual hecha por los religiosos de la Compañia de Jesus, en las provincias del Paraguay, Uruguay, y Tape... En Madrid: en la imprenta del Reyno, 1639, h.2r. Biblioteca Eusebio Francisco Kino 24343.

47 Fernando Camberos de Yegros, El heroe serafico San Pedro de Alcantara, glorioso timbre de la familia descalza de el gran patriarcha San Francisco de Assis. Relacion historica, y panegirica, de su vida, muerte, y Milagros... Impresso en Salamanca: en la imprenta de Francisco Garcia Onorato y San Miguel, 1723, h.24v. Biblioteca Eusebio Francisco Kino 24502.

48 Jaime Moll Roqueta, "Sobre el 'privilegio' a Cristóbal Plantin”, p. 818.

49 Fernando Bouza, "Dásele licencia y privilegio". Don Quijote y la aprobación de libros en el Siglo de Oro, pp. 36-37.

50 María Elena Bribiesca Sumano, Texto de paleografía y diplomática, pp. 125 y 137.

51 Alejandro Cañeque, "Cultura vicerregia y Estado colonial. Una aproximación crítica al estudio de la historia política de la Nueva España”, p. 12. 
en su potestad o en la figura y autoridad de las Audiencias. Ésta es una de las cuestiones que obligan a analizar con mayor cuidado el tipo de preliminares que encontramos en el impreso novohispano, especialmente las licencias de impresión, pues éstas son documentos emanados por el virrey aun cuando contengan todos los elementos de un privilegio: temporalidad, geografía y sanción punitiva. ${ }^{52}$ Podemos apreciar tales diferencias en los ejemplos siguientes:

CON LICENCIA Y PRIUILEGIO que la Congregación de la Assumpcion de Nuestra Señora del Collegio de la Compañía de JESUS de San Luis Potosí impenetro del Exmo. Señor Don Juan de Leiva, y de Ladrada, Conde de Baños, Virrey Lugarteniente de el Rey N. Señor, Governador, y Capitan General de esta Nueva-España, y Presidente de la Real Audiencia de ella, \&c. Con pena que su Excellencia impone en su decreto de perdimiento de moldes, para que otro ninguno pueda imprimir dicho Libro Quarto. ${ }^{53}$

El Excelentissimo Señor Conde de Galve, Virrey de esta Nueva-España. \&c. Diò su Licencia para la Impression de este Sermon. Como consta en su Decreto de Primero de Octubre de $1694 .^{54}$

En nuestra opinión se trata de mercedes concedidas por los virreyes y para evitar confusiones deberíamos nombrarlas de manera diferente, algo así como privilegio colonial. Tal necesidad se justifica porque es seguro que los territorios americanos que contaron con talleres tipográficos tuvieron que adaptar la normativa peninsular de imprenta a su propia realidad cultural, comercial y administrativa, como se aprecia en los productos novohispanos. Sin embargo, para poder determinar cualquier aspecto en materia legal debemos localizar y contrastar, en la medida de lo posible, los documentos que se hayan conservado de estos trámites en los archivos. ${ }^{55}$

De esta manera podríamos determinar con mayor certeza cómo se realizaron tales trámites ante la Audiencia de México, como adaptación a una normativa tan puntual. Por ejemplo, como funcionó el denominado "privilegio de cartillas” concedido al Hospital de los Naturales, institución que si

52 Fermín de los Reyes Gómez, "Con privilegio: la exclusiva de edición del libro antiguo español”, p. 170.

53 Explicación del libro quarto conforme a las reglas del arte de Antonio Lebrija con vn suplemento singular à las Relas generales... Con licencia, y privilegio Impresso en Mexico: En la Imprenta de Francisco Rodríguez Lupercio, 1664, h.1v. Biblioteca Eusebio Francisco Kino 016943.

54 Juan de Narvaes, Sermon que en la celebridad de la translacion del Cuerpo del glorioso Apostol de la India S. Francisco Xavier en la Parrochia de la Sancta Vera-cruz de esta Ciudad... Con licencia en Mexico: por la Viuda de Francisco Rodriguez Lupercio, 1694, h.6r. Biblioteca Eusebio Francisco Kino 19148. 
bien contó con el Real patronazgo no parece haber tenido tan particular prerrogativa, pero sí una curiosa solución dada por el virrey ${ }^{56}$ que beneficiaba tanto al Hospital como a los impresores entre el siglo XVII y XVIII. ${ }^{57}$

Dicha investigación en los archivos mexicanos también podrá mostrarnos quiénes, además del autor, tramitaban privilegios para la impresión de una obra, pues como ha mostrado la investigación de Bouza, que recién hemos mencionado, hay evidencias de que el trámite lo hacían también impresores, libreros, prelados, provinciales y otros interesados en este negocio editorial. ${ }^{58}$ Esto es así porque es necesario recordar que en esos tiempos los autores no gozaban de los derechos y reconocimientos que ahora tienen; además, debido a que imprimir era una profesión que se ejercía con mayor libertad se generó una fuerte competencia económica. De ahí que una forma de garantizar la estabilidad del taller haya sido la tramitación de un privilegio para una obra o para un tipo de obras. ${ }^{59}$ De esta forma un taller podía mantenerse con la obtención de un privilegio como el otorgado a los Zúñiga para las Guías de forasteros en la Nueva España. Un privilegio que, no debemos olvidar, fue otorgado en 1792 con exclusividad para imprimir durante toda su vida, ${ }^{60}$ una práctica que para esas fechas era ya extraña en la Península.

Sin embargo, tenemos pocas certezas sobre costos de producción frente a las ganancias porque no contamos todavía con evidencias suficientes para determinarlo, pero nuevos estudios nos ayudarán a dilucidar este aspecto. Es el caso de la tesis de doctorado de Manuel Suárez Rivera, ${ }^{61}$ la cual presenta datos para analizar y comparar las ganancias que tuvo un taller de imprenta como el de los Zúñiga y Ontiveros. No obstante, en ciertos periodos, como el siglo XVI, esto resulta imposible porque no se ha localizado información relativa a este tema y no tenemos esperanzas de hallarla dada la pérdida de documentación histórica. Lo que es cierto es que esa producción, en términos de tiradas, estaba determinada por el ritmo de composición en los talleres, aunque los datos hasta ahora obtenidos sólo nos permitan saber que se trató de una producción local con pocas aspiraciones de comercio internacional. Un dato que nos permite confirmar esa afirmación es la presencia de impresos novohispanos en las bibliotecas particulares e institucionales del territo-

56 Biblioteca Nacional de Antropología e Historia (BNAH), Hospital Real de Naturales, vol. 106, exp. 52, 226r.-227r.

57 Idalia García, "Entre plúteos y sombras: un recorrido por la materialidad de los impresos novohispanos”.

58 Bouza, op. cit., pp. 38-47.

59 Manuel José Pedraza Gracia, El libro español del Renacimiento: la vida del libro en las fuentes documentales contemporáneas, p. 208.

60 Manuel Suárez Rivera, El negocio del libro en Nueva España: los Zúñiga Ontiveros y su emporio tipográfico (1756-1825), p. 80.

61 Ibid., p. 314. 
rio novohispano, mientras que el análisis del mismo tipo de colecciones en otras latitudes no muestra esta presencia. También se trata de una producción que en ciertas ocasiones ha sido despreciada por su amplio contenido religioso.

Hoy tenemos mucha información sobre el funcionamiento de las prensas, ${ }^{62}$ tanta que podemos reproducir su funcionamiento. Así, sabemos que una prensa manual requiere para ponerse en marcha cuando menos de tres operarios: componedor, batidor y tirador. También que los procesos de impresión se hacían por facetas: composición, imposición y casado, y finalmente la tirada. ${ }^{63}$ Igualmente podemos entender estos procesos porque también se veían afectados por una legislación muy puntual que se elaboraba desde finales del siglo XV y que no terminará de definir la estructura y presentación de los impresos sino hasta principios del siglo XIX. ${ }^{64}$ Lo que es más importante es que los talleres de imprenta eran estructuras familiares de las cuales las mujeres formaban parte, lo que les permitió tomar el mando del negocio al entrar en la viudez.

Esas mujeres no pasaron de la cazuela a la prensa o a heredar los talleres para meramente casarse con uno de los operarios. Suponemos que al casarse con un impresor o al formar parte de la familia adquirirían los conocimientos necesarios de un mundo profesional del que después tendrían que hacerse cargo, como fue el caso de Brígida Maldonado, ${ }^{65}$ tan sólo una de las tantas viudas de impresores que han comenzado a generar interés, como sucede con las novohispanas, ${ }^{66}$ aunque también surgen notables ausencias en los estudios, exceptuando a Paula de Benavides, ${ }^{67}$ Inés Vázquez Infante de Borja $^{68}$ o Rosa Teresa de Poveda. ${ }^{69}$ Pero ese interés sobre su trabajo ha sido muy descriptivo y se refleja en pocos trabajos en vez de en una investigación más amplia que aborde no sólo su vida personal y profesional, sino el registro

62 Joseph Moxon, Mechanical Exercises or handy works. Applied to the Art of Printing. The second volumen...; Juan Joseph Sigüenza y Vera, Mecanismo del arte de la imprenta para facilidad de los operarios que le exerzan; Alonso Víctor de Paredes, Institución y origen del arte de la imprenta y reglas generales para los componedores; Jaime Moll Roqueta, "La imprenta manual"; Julián Martín Abad, "La técnica impresora".

63 Cristóbal Suárez de Figueroa, "Discurso CXI, de los Impressores", p. 367.

64 Fermín de los Reyes Gómez, El libro en España y América, legislación y censura: siglos XV y XVIII.

65 Natalia Maillard Álvarez y Clive Griffin, "Doña Brígida Maldonado, la Familia Cromberger, y la imprenta sevillana”.

66 Marina Garone Gravier, "Impresoras hispanoamericanas: un estado de la cuestión".

67 Ana Cecilia Montiel Ontiveros y Luz del Carmen Beltrán, "Paula de Benavides: impresora del siglo XVII. El inicio de un linaje".

68 Mercedes Isabel Salomón Salazar, "Los Borja: una dinastía de impresores en la Puebla de los Ángeles del siglo XVII. Un primer acercamiento".

69 Mabeel Hernández Mayen, Heredera de una imprenta familiar: Rosa Teresa de Poveda, viuda de Hogal. Un acercamiento a su vida y producción de 1741-1755. 
completo de toda su producción bibliográfica conocida, incluyendo el análisis de sus características distintivas. De ahí que resulte tan interesante pensar en la vida cotidiana que tomaba lugar en los talleres de impresión novohispanos, en donde familias y operarios convivían cercana y constantemente.

\section{Aperturas en un mUndo estructurado}

Las imprentas funcionaron igual que las estructuras gremiales que se practicaban en otros oficios, pero a la fecha no tenemos noticia de ninguna ordenanza que indique la existencia de un gremio dedicado a los impresores, encuadernadores y libreros en la Nueva España. Incluso los trabajos de Carrera y de $\mathrm{Zavala}^{70}$ no dan una sola noticia al respecto. Así que pese a esa apreciación ${ }^{71}$ no podemos afirmar tal condición pues las ordenanzas de cada gremio "se empeñan en convertirlas en organizaciones cerradas, jerárquicas y prácticamente monopólicas. Además de preocuparse de la calidad de sus productos, sus prescripciones se dirigen a limitar sus esferas de trabajo"; 72 cuestión que no parece encajar con lo que hasta ahora sabemos del mundo de la imprenta novohispana. Tampoco tenemos noticia de ninguna cofradía de los impresores en este territorio pero sí de una devoción: san Juan Evangelista, "ante portam latina" 73 que se veneraba "en el Monasterio de las Señoras Capuchinas" ${ }^{74}$ Este lugar fue el Convento de San Felipe de Jesús, fundado en el año de $1666 .^{75}$

La realidad de la Península no difiere mucho de la novohispana, pues sólo sabemos de pocas agrupaciones: la Hermandad de San Jerónimo de Mercaderes de Libros fundada en $1611,{ }^{76}$ que contaba con ordenanzas, y la Real Compañía de Impresores y Libreros del Reino, fundada en $1763 .^{77}$ Ciertamente ésta no era la realidad de otros territorios, como el francés, que bien han descrito Febvre y Martin $^{78}$ como un mundo laboral más organizado y con mayores requerimientos. Así lo han demostrado numerosos estudios de-

70 Manuel Carrera Estampa, Los gremios mexicanos: la organización gremial en Nueva España, 1521-1861, pp. 299-319; Ordenanzas del trabajo, siglos XVI y XVII

71 Gremios y cofradias en la Nueva España.

72 Guillermo Tovar de Teresa, "Consideraciones sobre retablos, gremios y artífices de la Nueva España en los siglos XVII y XVIII”, p. 8.

73 Victor Infantes, "La santidad tipográfica en la España del Siglo de Oro. Las honras poéticas a San Juan Evangelista, Patrón de los impresores”, pp. 253-254.

74 Gazeta de México, mayo de 1731, p. 329

75 Asunción Lavrin, Brides of Christ: Conventual Life in Colonial México, p. 359.

76 Javier Paredes Alonso, Mercaderes de Libros: cuatro siglos de historia de la Hermandad de San Gerónimo.

77 Diana M. Thomas, The Royal Company of Printers and Booksellers of Spain: 1763-1794.

78 Lucien Febvre y Henri-Jean Martin, La aparición del libro, pp. 143-191. 
dicados a los talleres españoles. ${ }^{79}$ Por su parte, los documentos hasta la fecha localizados nos permiten comprender que, efectivamente, los talleres de imprenta novohispanos funcionaban en su estructura como un gremio. Como ejemplo podemos ver un contrato de aprendizaje que se ha encontrado y en el que se puede leer:

En la çiudad de mexico a veinte (mutilado) de noviembrede mill Y seisçientos (mutilado) sesenta años ante el señor don francisco davila corregidor ordinario (mutilado) Por su magestad $\mathrm{Y}$ ante mi el escrivano publico $\mathrm{Y}$ testigos por pareçio un Yndiçuelo que mediante martin de alvear Ynterp[r]ete de La audiencia hordinaria dixo llamarse diego alonso Y ser natural del uaRio(sic) de santiago tatelolco de edad de catorçe años guerfano de padre (tachado) Y que de su boLuntad quiere aPrender oficio de Ympresor y Para Poder otorgar escritura Y visto porsu merçed Dixo que de ofiçio de la Real Justicia Le Ponia Y [para ser]viçio Y por aprendiz con el Licenciado Joan blanco [de Al]caçar YnPresor Y veZino desta dicha Ziudad por [el tien]Po de quatro años Primeros siguientes que corren $Y$ se quenten desde oY dia de la fecha desta en (ilegible) (mutilado)se Y durante ellos leade enseñar el dicho arte y ofiçio de Ymprimir Y tirar Y batir Ycomponer $Y$ todo lo Demas anezo a el dicho arte asta quesea oficial de[...]que Pueda travajar en la ParteY lugar donde qu[iesie] re $Y$ los dos años primeros cada mes pesso $Y$ medio los demas Restantes a dos pesos cadames $\mathrm{Y}$ comer $\mathrm{Y}$ ves[tir]se a su usso $\mathrm{Yssi}$ algun tienpo mas del dicho letuvi[ese]en su cassa $Y$ serviçio Le a de pagar Lo que suele ganar un ofiçial del dicho ofiçio Y estando Presente el dicho Joan blanco de alcaçar que Yo el escrivano publico doi fee [que] conosco azepto esta escriptura Y Reçivio en su cassa Yserviçio Y Por tal aPrendis a el dicho diego alonso Yndio Y se obliga[ba] De le enseñar el dicho arte Y Darle todo lo demas [con]ferido sin que falte cossa alguna. ${ }^{80}$

A pesar de esta información sabemos que los impresores españoles, al igual que los novohispanos, no tenían las exigencias jurídicas y sociales que implicaba esta forma de organización, como se aprecia en otros grupos profesionales como pintores o plateros, aunque en algunos territorios los impresores se asociaron para financiar una edición o para establecer pleitos jurídi$\cos ^{81}$ En Nueva España no hemos encontrado muchas noticias de este tipo de relaciones comerciales, salvo aquellas de Pedro Ocharte con Antonio de Espinosa y Antonio Ricardo, que conocemos gracias al proceso inquisitorial

79 Clive Griffin, "La carrera del impresor en la Edad Moderna: Pierre Regnier".

80 "Contrato de aprendizaje", Archivo General de Notarías, Notario 497, Juan Pérez de Ribera, vol. 3362 bis, fol. 370v. Agradezco a Natalia Maillard su generosidad al proporcionarme una copia digital de este documento y a Jesús Alfaro Cruz por su transcripción.

81 Natalia Maillard Álvarez, "Entre Sevilla y América. Una perspectiva del comercio del libro", p. 211. 
en el que se vieron implicados, ${ }^{82}$ información que confirman los libros conservados.

Sus relaciones fueron más bien de orden familiar y sirvieron para transmitir entre generaciones los aparejos de impresión y las prensas. Esta constante reaparición de grabados entre talleres ha dado lugar a supuestos préstamos de material tipográfico entre ellos. ${ }^{83}$ Debido al ambiente competitivo que existió entre los diferentes talleres, lo más probable es que pudiesen alquilarse o venderse piezas como viñetas o grabados calcográficos. Es decir, esta constante utilización de ornamentos tipográficos estaría justificada por los permanentes intercambios comerciales ${ }^{84}$ tanto como por la dependencia novohispana de los insumos necesarios para la producción bibliográfica que, suponemos, eran traídos desde Europa. Sin embargo, hasta que podamos localizar testimonios en este sentido, sería mejor no especular.

La forma de trabajo de los talleres de imprenta era bien conocida por la Corona, al menos en la Península, pues en noviembre de 1572 Felipe II mandó realizar, mediante provisión al Consejo de Hacienda, una inspección sobre la situación productiva de las prensas. ${ }^{85}$ Otro tanto mandó hacer el monarca con las librerías del reino en ese mismo año, lo que permitió "establecer un censo casi completo y la tipología de los libreros" 86 que comerciaban en el reino. Estas fiscalizaciones no consideraron los territorios americanos en los cuales las imprentas y librerías eran negocios muy recientes. La provisión para los talleres de impresión se envió a Toledo, Burgos, Medina del Campo, a las Universidades de Salamanca y de Alcalá de Henares, a Sevilla, a la Audiencia de Granada y a la Chancillería de Valladolid. Este interés habría sido motivado por las constantes quejas relacionadas con los múltiples errores con que se publicaban los libros. Con esta información se pretendía saber qué era lo que motivaba tan penosa situación en la producción bibliográfica. Esa consulta proporcionó a la Corona

un informe pormenorizado, comprensivo del número de talleres activos en cada caso, del número de impresores y de la capacidad técnica de cada taller, detallando el número de correctores, cajistas, batidores y tiradores, y evaluando su prepa-

82 Stols, Pedro Ocharte: el tercer impresor mexicano, pp. 21-22.

83 María Isabel Grañén Porrúa, "El ámbito socio-laboral de las imprentas novohispanas. Siglo XVI", p. 69.

84 Magdalena Chocano Mena, "Imprenta e impresores de Nueva España 1539-1700: límites económicos y condiciones políticas en la tipografía colonial americana", p. 5.

85 Reyes Gómez, op. cit., pp. 227-245.

86 José García Oro, Felipe II y los libreros: actas de las visitas a las librerías del reino de Castilla en 1572, p. 9. 
ración igualmente, pero también de los necesarios detalles sobre la maquinaria y el instrumental disponible, en particular las cajas de tipos. ${ }^{87}$

Como resultado de esta investigación se recomendó que se hicieran mayores tiradas y en buen papel, como se hacía en otros países. Sin embargo, esto no siempre fue posible precisamente porque esas averiguaciones de la Corona se hicieron justo con la motivación que propició el Concilio de Trento, que reformó el Breviario y el Misal en 1570, el cual genéricamente conocemos como el Nuevo Rezado y que significó por primera vez una difusión internacional de textos litúrgicos. ${ }^{88}$ Estos cambios ofrecieron un importante nicho comercial tanto para impresores como para libreros, quienes buscaron privilegios para imprimir y distribuir esos textos. Si bien los talleres españoles no contaron siempre con la gracia de la Corona para la producción de grandes tiradas, tampoco es cierto que estas concesiones fueran siempre entregadas a talleres extranjeros como el de Cristóbal Plantino en Flandes, quien "sobre todo se dedicaba a la publicación de obras eruditas en latín y también en los idiomas sagrados como el hebreo y griego". 89 También esas mercedes fueron concedidas a los Junta, familia de tradición italiana pero ya asentada en España, quienes en 1573 obtuvieron contrato para imprimir 4400 diurnales. $^{90}$

Los datos de la consulta sobre las imprentas españolas del siglo XVI nos permiten comprender qué tan cercanos a la situación laboral y producción podrían estar los talleres novohispanos en cuanto a operarios, prensas y material tipográfico. Pero también habría que considerar la información que nos aporta la otra consulta que se realizó en 1752 por el Juez de Imprentas Juan de Curiel, aunque ésta fue inspirada por diferentes motivos a los que se habían realizado 180 años antes. Como resultado de esta última consulta, Curiel elaboró un auto que regulaba la impresión de libros y que constó de 19 capítulos, documento que generó enormes problemas precisamente con impresores y mercaderes de libros porque las afectaciones podrían ser terribles para ese mercado.

Los cambios que pretendía este funcionario incluían que la licencia de impresión debía tramitarse para cualquier impreso, incluso los menores, que precisamente por su facilidad de producción (debido a su tamaño) y por su gran distribución significaban un ingreso seguro para los impresores. ${ }^{91}$ Sus

87 Julián Martín Abad, "Los talleres de imprenta españoles en época de Cervantes".

88 Jaime Moll Roqueta, "Plantino, los Junta y el 'Privilegio' del Nuevo Rezado", pp. 9-11.

89 Simon A. Voster, "Cristóbal Plantino y la literatura española de la Edad de Oro", p. 96

90 Moll, op. cit., pp. 16-17.

91 Silvia González-Sarasa Hernáez, "Delimitación conceptual y problemas terminológicos en torno a una tipología editorial del impreso antiguo”, pp. 5-7. 
propuestas también contenían la entrega de dos originales para constatar fidelidad, el asunto de las tasas que debían ser del libro y no de los pliegos (precio de venta), los porcones (alegaciones en derecho), las fes de erratas, las reimpresiones de cartillas, la participación inquisitorial, la obligatoriedad sobre la calidad del papel, la introducción de libros extranjeros y la venta de las bibliotecas de difuntos. ${ }^{92}$

A la fecha no tenemos noticia de que este mismo tipo de análisis sobre la actividad profesional haya sido de interés para la Corona en los territorios americanos que tenían talleres de imprenta, como el novohispano. Lo cierto es que no se ha hallado ninguna fuente que testimonie una realidad distinta en el aspecto laboral de las imprentas de la Nueva España, ni tampoco la existencia de una norma legal diferente a las que se aplicaban en la península (generadas entre 1502 y 1793). Por tal razón podemos suponer que los libros se debieron producir bajo la misma forma legal que se había establecido en la Pragmática de 1558 que ya hemos mencionado y que, a saber, fue la siguiente: revisión oficial y autorización del manuscrito; obtención de las licencias y privilegio (cuando procede); impresión del primer ejemplar (el príncipe); entrega de éste y del manuscrito base para la revisión del corrector; elaboración de la fe de erratas y de la tasa y finalmente la impresión de los siguientes ejemplares y del cuaderno de los preliminares de la edición.

Lo cierto es que los impresos novohispanos, el producto final, poseen características estructurales muy puntuales que desafían tal saber sobre la legislación de imprenta. Por ejemplo, los primeros impresos del siglo XVI (mal considerados como incunables) se diferencian muy poco de los producidos en España en ese mismo tiempo. Aspecto que no debería extrañar a nadie, pues todos los primeros operarios de prensa que llegaron a América eran europeos. Es decir, se habían formado y habían manufacturado en talleres del Viejo Mundo; era la única forma de producir libros que habían conocido y es justamente lo que se va a reflejar en los impresos. En efecto, un análisis detallado de estos impresos nos permite encontrar en su estructura, derivada directamente de su manufactura, mayores cercanías en el cumplimiento de la normativa aplicable como en tasas, licencias o aprobaciones.

Por su parte, a partir de 1600, los impresos producidos en la Nueva España comienzan a adquirir características propias y distintivas en su estructura aunque su calidad pueda considerarse muy inferior a la europea por la misma dependencia que hemos mencionado. ${ }^{93}$ Además habría que recordar que la Corona nunca autorizó la producción de papel para uso comercial en el vi-

92 Antonio Mestre, "Problemas con la censura. Informe de Mayans sobre el Auto de censura de libros establecido por Juan Curiel en 1752”, pp. 333-350.

93 Jaime Moll Roqueta, "Valoración de la industria editorial española del siglo XVI", p. 79. 
rreinato novohispano; sólo se tiene noticia de la existencia de un batán de papel en el convento agustino de Culhuacán, que podría emplearse para las prensas o la documentación de esa comunidad religiosa. ${ }^{94}$ Los impresores novohispanos dependieron entonces de su comercio en las redes comerciales de la Carrera de Indias. Las investigaciones que han estudiado el comercio libresco entre América y Europa documentan el envío de resmas de papel por los mismos mercaderes que comerciaban con libros. ${ }^{95}$ Asunto comercial que no ha sido del todo considerado en los estudios realizados sobre el papel en la Nueva España, pese a que se ha reconocido a los sistemas de monopolio que regían las políticas comerciales de la Corona española, que justificaron el registro en la carga y la descarga de las mercancías.

En cierta forma podríamos decir que estos impresos novohispanos ya no cumplen con la normativa de su época. Pero es importante considerar que esto fue resultado de la completa imposibilidad de cumplimiento debido a la lejanía territorial y, en consecuencia, la adopción de medidas propias tanto por las Audiencias como por el virrey, por ejemplo, lo correspondiente a la elaboración de la fe de erratas que debía realizar un corrector autorizado por la Corona, una tarea que era exclusiva potestad de funcionarios como Juan Vázquez de Mármol o los Murcia de la Llama. ${ }^{96} \mathrm{Al}$ respecto, no hemos encontrado documentación relacionada con un cargo similar como funcionario virreinal; por el contrario, sabemos que la corrección podían hacerla bachilleres contratados o incluso los propios autores. ${ }^{97}$

Todas estas medidas no parecen haber causado un conflicto de ninguna naturaleza entre las autoridades virreinales y los productores, afirmación que puede hacerse porque no hemos encontrado noticia de queja, disgusto o noticia relativa a este tema en la documentación peninsular. No obstante, este es un tema sumamente interesante que deberíamos abordar con mayor detalle. También desconocemos casi todo en materia de insumos: su calidad, procedencia y precio, pues como hemos precisado se trata de productos que se mueven en la Carrera de Indias. No debemos olvidar que ese comercio estaba regulado y, que así como se han encontrado los testimonios de las mercancías que se enviaban a América, las facturas correlativas a este intercambio se encuentran en los repositorios americanos.

94 Hans Lenz, Historia del papel en México y cosas relacionadas, pp. 81-83.

95 Maillard Álvarez, op. cit., pp. 223-224; Lenz, op. cit., pp. 29 y 34.

96 Fernando Bouza, "No puedo leer nada. El corrector general Juan Vázquez del Mármol y la cultura escrita del Siglo de Oro"; Félix Díaz Moreno, "El control de la verdad: los Murcia de la Llana, una familia de correctores de libros".

97 García, "Entre plúteos y sombras: un recorrido por la materialidad de los impresos novohispanos”. 
Lo poco que sabemos se deba quizá a la escasa atención que hemos prestado para recuperar este tipo de testimonios, que dan cuenta de las redes comerciales que se establecieron entre el Viejo y el Nuevo Mundo para dotar a los impresores de los elementos necesarios para garantizar la producción de libros, especialmente en cuanto a papel y tipos. De estos últimos, hasta donde tenemos noticia, no será sino hasta el siglo XVIII cuando comienzan a producirse materiales tipográficos en la Colonia por fundidores de letras y abridores de punzones que forman ya un grupo particular. ${ }^{98}$ Lo que sí sabemos es que su disponibilidad de material tipográfico era más o menos similar a la peninsular, pues encontramos citadas las familias tipográficas en inventarios y tasaciones comerciales, así como noticias del envío de material tipográfico desde Europa. ${ }^{99}$

El otro elemento importante para la producción fue la tinta, que hasta donde sabemos fue producida en cada taller según una fórmula conocida por la familia y cuya transmisión fue generacional. ${ }^{100}$ Por esa razón los estudios científicos contemporáneos pueden diferenciar los productos de cada taller, pues la tinta para imprimir era diferente de la de escribir, requería de una sustancia aceitosa.

Es muy posible que la documentación conservada que recién hemos comenzado a identificar nos aporte mayores datos no sólo sobre las relaciones comerciales o familiares de las imprentas novohispanas, sino que permita resolver múltiples interrogantes que no hemos logrado contestar. Por ejemplo, siempre nos hemos preguntado quiénes realizaban el trabajo de impresión para la Audiencia, como los bandos o edictos, pues por su naturaleza tipográfica se trata de objetos que no suelen tener ningún tipo de dato que nos ayude a identificar al taller de impresión. Tal nebulosidad histórica puede comenzar a despejarse con la localización de documentos como el que aquí transcribimos:

Nos los inquisidores Appostolicos etcétera mandamos Avos Martin de Briviesca Roldan Reçeptor de este Santo ofiçio que de qualesquier maravedis que estubieren en la arca de tres llaves que esta en la camara del secreto de esta Inquisicion deys y pagueys Al Bachiller Juan Blanco ympresor vezino de esta çiudad ocho pesos de oro comun en Reales que a deaver y Se le deben por los edictos que ymprimio en diez de este presente mes de Abril para Recoger los escriptos tratados y papeles que hasta aora sean escripto conçernientes al nombramiento que hizo el Reino de Castilla de Patrona a la Beata [tachado Madre] theresa de Jhesus y prohiviçion para que de aqui adelante no se ympriman y tomad su carta de pago Con la qual y es-

98 AGN, Reales cédulas originales vol. 121, exp. 32.

99 Marina Garone Gravier, "A vos como protectora busca la imprenta ¡Oh María! pues de Christo en la agonía fuiste libro é impresora: una muestra tipográfica novohispana desconocida (1782)", p. 250.

100 Pedraza, op. cit., pp. 240-241. 
ta nuestra librança mandamus al contador o persona que tomare las quentas de la dicha Arca y vuestro cargo os admita y pase en ellas los dichos ocho pesos fecho en la çiudad de Mexico en onze de Abril de mill y seiscientos y diez y nueve Annos. ${ }^{101}$

La información que nos ofrecen estos testimonios resulta crucial para reconstruir justamente aspectos económicos de las imprentas novohispanas. Los recibos de pago dan cuenta de quiénes son los impresores de todo ese material documental que conocemos genéricamente como impresos menores. Un conjunto de impresos que todavía se conservan en los archivos, incluso sin usarse. ${ }^{102}$ Productos tipográficos cuya función en la vida cotidiana de los novohispanos no debemos desestimar en lo absoluto, y que representaron ingresos constantes para los impresores. Veamos por ejemplo este caso que aparece registrado en una testamentaria: "Por veinte y seis pesos pagados a el Impresor y repartidor de 400 cartas que se imprimieron para Convites à el entierro". 103

También podemos encontrar otros datos más interesantes que nos pueden ayudar a comprender el costo mismo de las impresiones. Así, entre los papeles de los jesuitas encontramos una nota que dice:

Ymporte de la impression de 290 exemplares de la Lengua Opata, para el Padre Procurador Joseph Ydalgo. hizo dicha lengua 21 pliegos y cuartilla de letra Atanasia que vale a 8 pesos cada pliego.

Planta $[170 \text { pesos }]^{104}$

Esta cuenta de 1750 debe referirse a la obra del jesuita Natal de Lombardo, Arte de la lengua teguima: vulgarmente llamada opata, impresa por Miguel

101 "Carta de pago de Juan Blanco de Alcazar (1619)", AGN, Inquisición vol. 1573, exp. 59, 1r. Al año siguiente este impresor seguía trabajando para el Santo Oficio imprimiendo los edictos, en 1620 le pagaron 9 pesos. "Libranza de pago que otorgan los inquisidores de 9 pesos en favor de Juan Blanco de Alcaraz (1620), AGN, Indiferente Virreinal Caja 5025, exp. 120, fol. 1r. Expediente digitalizado disponible en http://www.agn.gob.mx/guiageneral/ [Fecha de consulta: abril de 2015] Estos documentos ya habían sido localizados por Ken Ward, quien da cuenta del primer pago a este impresor en 1615. Ken Ward, Where They Coin Money and Print Books, p. 48.

102 "Mandamiento de prisión, embargo de bienes, y cárcel contra heréticos y apostatas. Tribunal del Santo Oficio de la Inquisición”, AGN, Indiferente Virreinal, Caja 1210, exp. 17, 7 ejemplares sin utilizar. Expediente digitalizado disponible en http://www.agn.gob.mx/guiageneral/ [Fecha de consulta: abril de 2015]

103 "Descripción de los bienes que quedaron por fin y muerte del Capitán José Domingo de Valdivieso, caballero que fue del Orden de Santiago (1794)”, AGN, Civil 1885, Legajo 189, fol. 12v. El impresor fue Manuel Antonio Valdés.

104 "Correspondencia sobre Desembarco de misioneros en Veracruz; importe de impresiones; diligencias sobre multas; recepción de libros; matrimonios; enviada por los misioneros jesuitas a los padres Joseph de Hidalgo del colegio de San Andres, Ygnacio Mozara del colegio del Espíritu Santo de Puebla y al padre Joseph Carrillo (1750)", AGN, Indiferente Virreinal, Caja 4198, exp. 10, fol. 15r. Expediente digitalizado disponible en http://www.agn.gob.mx/guia general/ [Fecha de consulta: abril de 2015] 
de Ribera en 1702. Obra de la que aparentemente existen sólo tres ejemplares en el mundo: en Estados Unidos, Francia y México, ${ }^{105}$ y cuyo manuscrito autógrafo se conserva en la Newberry Library como parte de la colección Edward E. Ayer Manuscript. ${ }^{106}$ Podría tratarse de esta obra, porque el otro texto dedicado a esta lengua de Sonora es del también jesuita Manuel de Aguirre y fue impreso quince años después de esta nota. ${ }^{107}$ También es cierto que existe noticia de un vocabulario en esta lengua publicado el mismo año y por el mismo autor, ${ }^{108}$ del que no he encontrado noticia de algún ejemplar superviviente. Resulta interesante la cotización porque la edición conservada del Arte de 1702, según los catálogos bibliotecarios, fue impreso en cuarto y tiene 14 hojas de preliminares y 252 páginas. Es decir, el libro completo estaría compuesto por aproximadamente 35 pliegos impresos. La cotización nos confirma que los documentos preliminares no contaban en los precios de producción de las impresiones. No obstante, si consideramos tan sólo los pliegos empleados en el texto de la obra de 1702, que serían 31 y medio, las cuentas no cuadran.

Cabría preguntarse si esta cuenta se refiere a una reimpresión de la que no tenemos noticia ni ejemplar conservado o de otra obra que no es de Lombardo. Las reimpresiones no fueron extrañas en la imprenta antigua y al hacerlas se trataba de que la última impresión coincidiera con alguna anterior incluso en las líneas de texto. Es el caso de todas las reimpresiones que realizaron diferentes impresores de la obra de Alonso de Velasco Exaltacion de la divina misericordia en la milagrosa renovacion de la soberana imagen de Christo Señor Nuestro Crucificado que se venera en la Iglesia del Convento de Señor San José de Religiosas Carmelitas Descalzas, que se imprimió por primera vez en 1699 y de la que se hicieron reimpresiones en 1724, 1776, 1790, 1807, 1810 y $1820 .{ }^{109}$ De esta obra también existe una edición de 1729 , que se ha considerado novohispana pero que en realidad se trata de un impreso sevillano.

105 En la Bancroft Library de la Universidad de California en Berkeley x PM4136 .L6, en la Biblioteca Nacional de Francia RES M-X-38 (FRBNF30829451) y en la Biblioteca Pública del Estado de Jalisco 497 LOM. Este último ejemplar forma parte de la Colección de Libros de Lenguas Indígenas, reconocido como Memoria del Mundo en el año 2007. El autor nació en Calabria en 1647 y murió en Puebla en 1704. Lombardo vivió como misionero con los ópatas de Sonora, durante más de veintiséis años a finales del siglo XVII.

106 VAULT Ayer MS 164. Información diponible en http://www.newberry.org/ [Fecha de consulta: abril de 2015].

107 Manuel Aguirre (S. I.), Doctrina Christiana y platicas doctrinales, traducidas en lengua opata... México: Colegio de San Ildefonso, 1765. Se puede consultar la versión digital de la John Carter Brown Library en https://archive.org/details/doctrinachristia00agui [Fecha de consulta: abril de 2015] El autor nació en Pamplona en 1715, fue misionero en Sonora desde 1750 y murió un año después de la expulsión.

108 Natal Lombardo (S. I.), Vocabulario de la lengua teguima y platicas doctrinales en ella... México, 1702, 4\% . Bibliotheca Americana, p. 436

109 En 1699 fue impresa por María de Benavides, viuda de Juan de Ribera, en 1724 por los Herederos de Miguel de Ribera, en 1776 y 1790 por Joseph de Jáuregui, en 1807 y 1810 por Mariano de Zúñiga y Ontiveros y, finalmente en 1820 por Alexandro Valdés. 
Este último, impreso por Francisco Sánchez Reciente, sigue el mismo modelo de las reimpresiones novohispanas. ${ }^{110}$

La nota o cotización que estamos mencionando fue enviada al jesuita Joseph Hidalgo, quien fue Procurador de Misiones hasta antes de la expulsión de 1767. Este cargo implicó la responsabilidad de hacer llegar a las misiones jesuitas desde vestimentas, chocolate y canela, hasta cuadros y libros. El dato mencionado, que se refiere a la impresión, agrega también información valiosa relativa al costo del papel, cubierta y encuadernación:

Papel 212 manos y media, de las cuales son 160 manos a 27 y 92 manos y media, a 2 reales la mano [63 pesos 1 real]

Ytem para cubierta 10 manos 2 reales la mano [2 pesos 4 reales]

Encuadernacion a 20 pesos el siento [90 pesos]

Suma [289 pesos 9 reales]

Como se puede apreciar con estas breves líneas, el universo de las imprentas novohispanas presenta todas estas grietas que se convierten en posibilidades de conocimiento para la cultura escrita. Es importante anotar que en esta historia cuentan tanto los testimonios como los productos, los libros que se produjeron. Éstos deberían considerarse más en los estudios porque son la parte material de una realidad histórica que aún nos asombra. Más allá del nombre de aquellos que pudieron estamparlo en una portada, queda el trabajo de hombres, mujeres y niños que no deberíamos olvidar, una muestra del valor que damos a su esfuerzo como un legado bibliográfico y cultural.

\section{BiBLIOGRAFÍA}

Abad, Julián Martín, "La técnica impresora”, en José Manuel Lucía Mejías, Aquí se imprimen libros: la imprenta en la época del Quijote, Madrid, Imprenta Artesanal Ollero y Ramos, 2004, pp. 11-34.

__ , "Los talleres de imprenta españoles en época de Cervantes", en Don Quijote en el campus. Tesoros complutenses, José Manuel Lucía Mejías (coordinación de la exposición virtual), Universidad Complutense de Madrid, 2005. Disponible en: http://biblioteca. ucm.es/foa/exposiciones/15Quijote/estudio02.htm [Fecha de consulta: junio de 2013]. 
Arrom, Silvia Marina, "Historia de la mujer y de la familia norteamericanas”, en Historia Mexicana, vol. 42, núm. 2, 1992, pp. 379-418. Disponible en: http://www.aleph.org.mx/jspui/bitstream/56789/ 28595/1/42-166-1992-0379.pdf [Fecha de consulta: julio de 2013].

Bouza, Fernando, "Dásele licencia y privilegio". Don Quijote y la aprobación de libros en el Siglo de Oro, Madrid, Akal, 2012.

_ _ "No puedo leer nada. El corrector general Juan Vázquez del Mármol y la cultura escrita del Siglo de Oro", en Syntagma: Revista del Instituto de Historia del Libro y de la Lectura, núm. 0, 2002, pp. 19-45.

Bribiesca Sumano, María Elena, Texto de paleografía y diplomática, Toluca, Universidad Autónoma del Estado de México, 2002.

Cañeque, Alejandro, "Cultura vicerregia y Estado colonial. Una aproximación crítica al estudio de la historia política de la Nueva España”, en Historia Mexicana, vol. 51, núm. 1, julio-septiembre, 2001, pp. 5-57. Disponible en http://codex.colmex.mx:8991/exlibris/ aleph/a18_1/apache_media/GHEYYAAV1N39M2I8I477M7UE3 P4DTY.pdf [Fecha de consulta: noviembre de 2013].

Carrera Estampa, Manuel, Los gremios mexicanos: la organización gremial en Nueva España, 1521-1861, México, EDIAPSA, 1954.

Castañeda García, Carmen, Imprenta, impresores y periódicos en Guadalajara, 1793-1811, México, Editorial Ágata, 1999.

Chocano Mena, Magdalena, "Imprenta e impresores de Nueva España 1539-1700: límites económicos y condiciones políticas en la tipografía colonial americana”, en Historia Social, núm. 23, 1995, pp. 3-19.

Cid Carmona, Víctor, Antonio Ricardo: impresor de dos ciudades, México y la Ciudad de los Reyes, tesis de Maestría en Bibliotecología y Estudios de la Información, UNAM, Facultad de Filosofía y Letras, 2006. Disponible en: http://132.248.67.65:8991/F/-/?func=findb-0\&local_base=TES01 [Fecha de consulta: julio de 2013].

Cruz Soto, Rosalba, "Los periódicos del primer periodo de vida independiente (1821-1836)", en Belem Clark de Lara y Elisa Speckman Guerra (eds.), La república de las letras: asomos a la cultura escrita del México decimonónico, vol. 2, México, UNAM, 2005, pp. 57-76.

Delgado Casado, Juan, Diccionario de impresores españoles, siglos XVXVII, Madrid, Arco Libros, 1996.

Díaz Moreno, Félix, "El control de la verdad: los Murcia de la Llana, una familia de correctores de libros", en Arbor, Ciencia, Pensamiento y Cultura, vol. 185, núm. 740, 2009, pp. 1301-1311. Disponible en: http://arbor.revistas.csic.es/index.php/arbor/article/view 1396/397 [Fecha de consulta: noviembre de 2013].

Elliot, Simon y Jonathan Rose (ed.), A Companion to the History of the Book, Singapore, Wiley \& Blackwell, 2009.

Fernández de Lizardi, José Joaquín, Obras, vol. 13, México, UNAM, 1995. 
Febvre, Lucien y Henri-Jean Martin, La aparición del libro, México, FCE, 2005.

Gacto, Enrique, "Libros venenosos. Sobre los principios doctrinales de la censura inquisitorial”, en Enrique Gacto Fernández (coord.), Inquisición y censura: el acoso a la inteligencia en España, España, Dykinson, 2006, pp. 21-55.

García, Idalia, Secretos del estante: elementos de descripción bibliográfica del libro antiguo, México, CUIB, 2011.

_ - "Retazos en la vida de una impresora novohispana: Rosa Teresa de Poveda, viuda de Hogal”, en Marina Garone Gravier (comp.), Las otras letras, mujeres impresoras en la Biblioteca Palafoxiana, Puebla, Secretaría de Cultura del Estado de Puebla, 2009, pp. 40 48. Disponible en: http://unam.academia.edu/IdaliaGarcía [Fecha de consulta: julio de 2013].

__ , "Entre plúteos y sombras: un recorrido por la materialidad de los impresos novohispanos", en Clive Griffin y Juan Carlos Conde (coords.), Simposio el libro en el mundo hispánico: nuevas tendencias y direcciones, University of Oxford, 2010. En prensa.

_- "Tentaciones herejes en instituciones religiosas: el control inquisitorial en las bibliotecas novohispanas", en Primer Coloquio magia, brujería y herejía en la Nueva España (Siglos XVI-XIX), Escuela Nacional de Antropología e Historia, agosto de 2013. Texto inédito.

García Icazbalceta, Joaquín, Bibliografía mexicana del siglo XVI, México, FCE, 1954.

García Oro, José, Felipe II y los libreros: actas de las visitas a las librerías del reino de Castilla en 1572, Madrid, Editorial Cisneros, 1997.

__ La Monarquía y los libros en el Siglo de Oro, Alcalá, Universidad, Centro Internacional de Estudios Históricos Cisneros, 1999.

Garone Gravier, Marina, "A vos como protectora busca la imprenta ¡Oh María! pues de Christo en la agonía fuiste libro é impresora: una muestra tipográfica novohispana desconocida (1782)", en Gutenberg-Jahrbuch, vol. 20/21, 2012, pp. 229-252.

_- "Impresoras hispanoamericanas: un estado de la cuestión", en Boletín de la Real Academia de las Buenas Letras de Barcelona, vol. 51, 2008, pp. 451-471. Disponible en: http://www.raco.cat/index. php/BoletinRABL/article/view/191317 [Fecha de consulta: julio de 2013].

Gazeta de México. México: Por Joseph Bernardo de Hogal, 1728-1742.

González Sánchez, Carlos Alberto, "Cultura escrita y nueva historia cultural: paradigmas y realidades", en Erebea. Revista de Humanidades y Ciencias Sociales, 2012, pp. 5-27. Disponible en: http://ra bida.uhu.es/dspace/bitstream/handle/10272/6323/Cultura_escri ta.pdf? sequence $=2$ [Fecha de consulta: julio de 2013]. 
González-Sarasa Hernáez, Silvia, "Delimitación conceptual y problemas terminológicos en torno a una tipología editorial del impreso antiguo”, en Anales de Documentación, vol. 14, núm. 2, 2011, pp. 114. Disponible en: http://digitum.um.es/xmlui/handle/10201/2 5189 [Fecha de consulta: noviembre de 2013].

Grañén Porrúa, María Isabel, "El ámbito socio-laboral de las imprentas novohispanas. Siglo XVI", en Anuario de Estudios Americanos, núm. 48, 1991, pp. 49-94.

— Los grabados en la Obra de Juan Pablos: primer impresor de la Nueva España, 1539-1560, México, ADABI, FCE, 2010.

- y Juan Pascoe, Francisca Flores y la imprenta en Oaxaca, 16851720, México, Librería Grañén Porrúa, 2004.

Gremios y cofradias en la Nueva España, México, INAH, Museo del Virreinato, información del mes de julio, 1996.

Griffin, Clive, "La carrera del impresor en la Edad Moderna: Pierre Regnier", en La memoria de los libros: estudios sobre la bistoria del escrito y de la lectura en Europa y América, t. 1, Salamanca, Instituto de Historia del Libro y de la Lectura, 2004, pp. 383-392.

— Los Cromberger: la historia de una imprenta del siglo XVI en Sevilla y Mejico, Madrid, Ediciones de Cultura Hispánica, 1991.

—. Oficiales de imprenta, berejía e inquisición en la España del siglo XVI, Madrid, Imprenta Artesanal Ollero \& Ramos, 2009.

Hernández Mayen, Mabeel, Heredera de una imprenta familiar: Rosa Teresa de Poveda, viuda de Hogal. Un acercamiento a su vida y producción de 1741-1755, tesis de Licenciatura en Ciencias de la Información Documental, UAEMX, Facultad de Humanidades, 2011.

Ibarra, Ana Carolina, "El desarrollo de la imprenta”, en Historia de la literatura mexicana: la cultura letrada en la Nueva España del siglo XVII, vol. 2, México, Siglo XXI, 2002, pp. 69-84.

Infantes, Victor, "La santidad tipográfica en la España del Siglo de Oro. Las honras poéticas a San Juan Evangelista, Patrón de los impresores", Península. Revista de Estudos Ibéricos, núm. 2, 2005, pp. 251-296. Disponible en http://ler.letras.up.pt/uploads/ficheiros/2967.pdf [Fecha de consulta: noviembre de 2013].

Lavrin, Asunción, Brides of Christ: Conventual Life in Colonial Mexico, Stanford, Stanford University Press, 2008.

Lenz, Hans, Historia del papel en México y cosas relacionadas, 1525 1950, México, Miguel Ángel Porrúa, 1990.

Lyons, Martin, "New directions in the History of Written Culture", Culture E History Digital Journal, vol. 1, núm. 2, 2012, pp. 1-9. DOI: http://dx.doi.org/10.3989/chdj.2012.007 [Fecha de consulta: julio de 2013].

Maillard Álvarez, Natalia, "Entre Sevilla y América. Una perspectiva del comercio del libro", en Gregorio Salinero (comp.), Mezclado y sospechoso: movilidad e identidades, España y América (siglos XVI-XVIII), Madrid, Casa Velázquez, 2005, pp. 209-228. 
Maillard Álvarez, Natalia y Clive Griffin, “Doña Brígida Maldonado, la Familia Cromberger, y la imprenta sevillana”, en Muses de la Impremta: La dona $i$ les arts del llibre. Segles XVI-XIX [Exposición], Barcelona, Museo Diocesano, 2009, pp. 91-128.

Maza, Francisco de la, Enrico Martínez: cosmógrafo e impresor de Nueva España, México, UNAM, 1991.

Medina, José Toribio, Historia de la imprenta en los antiguos dominios españoles de América y Oceanía, t. I, pról. de Guillermo Feliu Cruz; complemento bibliográfico de José Zamudio Z., Santiago de Chile, Fondo Histórico y Bibliográfico José Toribio Medina, 1958. Disponible en: http://www.cervantesvirtual.com/obra/historia-de-la-imprenta-en-los-antiguos-dominios-espanoles-de-ame rica-y-oceania-tomo-i--0/ [Fecha de consulta: junio de 2013].

—_, La imprenta en México, 1539-1821, México, UNAM, 1989.

Mestre, Antonio, "Problemas con la censura. Informe de Mayans sobre el Auto de censura de libros establecido por Juan Curiel en 1752", en El mundo intelectual de Mayans, Oliva, Ayuntamiento, 1978, pp. 333-350. Disponible en: http://bivaldi.gva.es/es/corpus/unidad. $\mathrm{cmd}$ ? idUnidad $=56611 \&$ idCorpus $=20000 \&$ posicion $=1[$ Fecha $\mathrm{de}$ consulta: junio de 2013].

Millares Carlo, Agustín y Julián Calvo, Juan Pablos: primer impresor que a esta tierra vino, México, Miguel Ángel Porrúa, 1953.

Moll Roqueta, Jaime, "La imprenta manual”, en Pablo Andrés y Sonia Garza (eds.), Imprenta y crítica textual en el Siglo de Oro, Valladolid, Universidad, Centro para la Edición de los Clásicos Españoles, 2000, pp. 13-27.

__, “Sobre el 'privilegio' a Cristóbal Plantin”, en Francisco Javier Aguirre González de Durana (coord.), Homenaje a Justo García Morales: miscelánea de estudios con motivo de su jubilación, Madrid, Asociación Española de Archiveros, Bibliotecarios, Museólogos y Documentalistas, 1987, pp. 809-819.

__, "Plantino, los Junta y el 'Privilegio' del Nuevo Rezado”, en Hans Tromp y Pedro Peira (eds.), Simposio Internacional sobre Cristóbal Plantino (18, 19 y 20 de enero de 1990), Madrid, Universidad Complutense, 1990, pp. 9-26. Disponible en: http://www. cervantesvirtual.com/obra-visor/plantino-los-junta-y-el-privilegiodel-nuevo-rezado/html/b3abd1fd-0d80-487f-bd05b3239822654e_ 5.html\#I_0_[Fecha de consulta: marzo de 2014].

__ "Valoración de la industria editorial española del siglo XVI", en Livre et Lecture en Espagne et France sous l'ancien Régime: coloque de la Casa de Velazquez, París, Casa de Velázquez, 1981, pp. 79-84.

Montiel Ontiveros, Ana Cecilia, La imprenta de María Fernández de Jáuregui: testigo y protagonista de los cambios en la cultura impresa durante el periodo 1801-1817 en México, Madrid, Instituto Universitario de Investigación Ortega y Gasset, 2011. 
Montiel Ontiveros, Ana Cecilia y Luz del Carmen Beltrán, "Paula de Benavides: impresora del siglo XVII. El inicio de un linaje", en Contribuciones desde Coatepec, núm. 10, 2006, pp. 103-115. Disponible en: http://revistacoatepec.uaemex.mx/index.php/contribuciones/article/view/115/110 [Fecha de consulta: noviembre de 2013].

Moxon Joseph, Mechanical Exercises or handy works. Applied to the Art of Printing. The second volumen..., London, Printed for Joseph Moxon, 1683.

Ordenanzas del trabajo, siglos XVI y XVII, selec. y notas de Silvio Zavala, México, Elede, 1947.

Paisano Rodríguez, María del Refugio, Pedro Balli, cuarto impresor novohispano: estudio histórico-bibliotecológico, tesis de Maestría en Bibliotecología y Estudios de la Información, UNAM, Facultad de Filosofía y Letras, 2011. Disponible en: http://132.248.67.65: 8991/F/-/?func=find-b-0\&local_base=TES01 [Fecha de consulta: julio de 2013].

Paredes, Alonso Víctor de, Institución y origen del arte de la imprenta y reglas generales para los componedores, ed. y pról. de Jaime Moll, Madrid, El Crotalón, 1984.

Paredes Alonso, Javier, Mercaderes de Libros: cuatro siglos de historia de la Hermandad de San Gerónimo, Madrid, Fundación Germán Sánchez Ruipérez, 1989.

Pascoe, Juan, Cornelio Adrián César, impresor en México, México, Taller Martín Pescador-Redacta, 1992. Parte de este texto se encuentra disponible en http://blogs.lib.utexas.edu/primeroslibros /files/Cornelis_Adriaens_Keyser.pdf [Fecha de consulta: junio de 2013].

_- José María Idiáquez, impresor en el Oratorio de la Congregación de San Felipe Neri de Oaxaca, Oaxaca, Fundación Harp Helú, 2011.

— L La obra de Enrico Martínez, México, Taller Martín Pescador, 1996.

Pedraza Gracia, Manuel José, El libro español del Renacimiento: la vida del libro en las fuentes documentales contemporáneas, Madrid, Arco Libros, 2008.

Reyes Gómez, Fermín de los, "Con privilegio: la exclusiva de edición del libro antiguo español”, en Revista General de Información y Documentación, vol. 11, núm. 2, 2001, pp. 163-200. Disponible en: http://revistas.ucm.es/index.php/RGID/article/view/11131 [Fecha de consulta: julio de 2013].

—_, El libro en España y América, legislación y censura: siglos XV y XVIII, Madrid, Arco Libros, 2000.

Rodríguez Domínguez, Guadalupe, "Avance para una nueva tipobibliografía mexicana: sobre la Doctrina de Gante y el Vocabulario de Molina, impresos por Juan Pablos", en Pecia complutense, vol. 10, núm. 19, 2013, pp. 82-96. Disponible en: http://eprints.ucm. es/22248/1/pecia_19-3.pdf [Fecha de consulta: julio de 2013]. 
Sabin, Joseph, Bibliotheca Americana: A Dictionary of Books Relating to America, from Its Discovery to the Present Time, vol. 10, New York, Sabin and Sons, Bibliographical Society of America, 1878.

Salomón Salazar, Mercedes Isabel, "Los Borja: una dinastía de impresores en la Puebla de los Ángeles del siglo XVII. Un primer acercamiento", en Miradas a la cultura del libro en Puebla: bibliotecas, tipógrafos, grabadores, libreros y ediciones en la época colonial, México, Consejo Estatal para la Cultura y las Artes de Puebla, 2013, pp. 205-242.

Sarabia Viejo, María Justina, "La imprenta Hogal: religión y cultura ilustrada en el México del siglo XVIII”, en Jesús-María Nieto Ibáñez y Raúl Manchón Gómez (coords.), El bumanismo español entre el viejo mundo y el nuevo, España, Universidad de León, Universidad de Jaén, 2008, pp. 455-490.

Sigüenza y Vera, Juan Joseph, Mecanismo del arte de la imprenta para facilidad de los operarios que le exerzan, ed. facsímil (Madrid, Imprenta de la Compañía, 1811), Madrid, Tipus Almarabu, 1992.

Stols, Alexander, Antonio de Espinosa: el segundo impresor mexicano, México, UNAM, 1989.

—-, Pedro Ocharte: el tercer impresor mexicano, México, UNAM, 1990.

Suárez de Figueroa, Cristóbal, "Discurso CXI, de los Impressores", en Plaza vniversal de todas ciencias y artes..., Madrid, Luis Sánchez, 1615. Disponible en: https://books.google.com.mx/books?id=Hrl gIgTsNd8C\&dq=crist $\%$ C3 $\%$ B3bal $\% 20$ su $\%$ C3\%A1rez $\% 20 \mathrm{de} \% 20$ figueroa\&hl=es\&pg $=\mathrm{PR} 9 \#_{\mathrm{v}}=$ onepage $\& \mathrm{q} \& \mathrm{f}=$ false $[\mathrm{Fech}$ de consulta: julio de 2013].

Suárez de la Torre, Laura, "La producción de libros, revistas, periódicos y folletos en el siglo XIX", en Belem Clark de Lara y Elisa Speckman Guerra (eds.), La república de las letras: asomos a la cultura escrita del México decimonónico, México, UNAM, vol. 2, 2005, pp. 9-25.

Suárez Rivera, Manuel, Felipe y Mariano de Zúñiga y Ontiveros: impresores ilustrados y empresarios culturales (1761-1825), tesis de Licenciatura en Historia, UNAM, Facultad de Filosofía y Letras, 2005. Disponible en: http://tesis.unam.mx/F [Fecha de consulta: julio de 2013].

__., El negocio del libro en Nueva España: los Zúñiga Ontiveros y su emporio tipográfico (1756-1825), tesis de Doctorado en Historia, UNAM, Facultad de Filosofía y Letras, 2013. Disponible en: http:// tesis.unam.mx/F [Fecha de consulta: noviembre de 2013].

Thomas, Diana M., The Royal Company of Printers and Booksellers of Spain: 1763-1794, Nueva York, The Whistson Publishing Company, 1984. 
Tovar de Teresa, Guillermo, "Consideraciones sobre retablos, gremios y artífices de la Nueva España en los siglos XVII y XVIII”, en Historia Mexicana, vol. 34, núm. 133, julio-septiembre, 1984, pp. 5-40. Disponible en: http://codex.colmex.mx:8991/exlibris/aleph/a18 _1/apache_media/M4HY344A258EE3ICXXSFUH6UPVK4VG. pdf [Fecha de consulta: junio de 2013].

Voster, Simon A., "Cristóbal Plantino y la literatura española de la Edad de Oro”, en Hans Tromp y Pedro Peira (eds.), Simposio Internacional sobre Cristóbal Plantino, Madrid, Universidad Complutense, 1990, pp. 95-122.

Ward, Kenneth C., "Conjeturas sobre los orígenes de la imprenta en Puebla”, en Marina Garone Gravier (ed.), Miradas a la cultura del libro en Puebla: bibliotecas, tipógrafos, grabadores, libreros y ediciones en la época colonial, México, Gobierno del Estado de Puebla, Educación y Cultura, UNAM, 2012, pp. 161-204.

, Where They Coin Money and Print Books: The Calderón Family Printing Dynasty, 1631-1732, diss., University of Texas, 2013.

Whittaker, Martha Ellen, Jesuit Printing in Bourbon Mexico City. The Press of Colegio de San Ildefonso, 1748-1767, diss., University of California, Berkeley, 1998. 